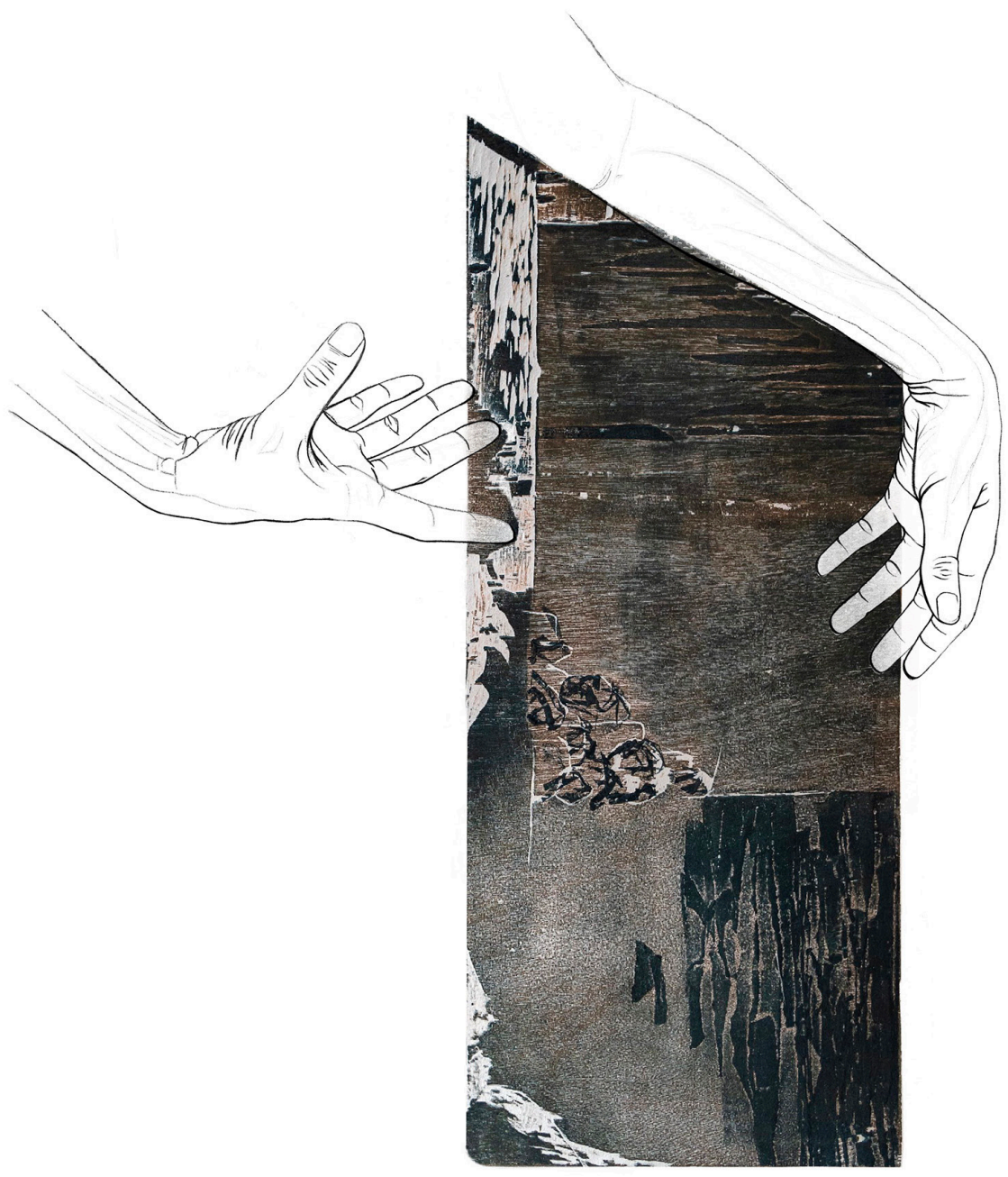


AUTORa: Olalla Cortizas 


\title{
"Este animal aflito"": leitura de três últimos homens em tempos apocalípticos pelas mãos de Mary Shelley, Pepetela e Miguel Real
}

\author{
Sofia de Melo Araújo \\ Instituto Politécnico do Porto / CETAPS / CITCEM / ILC-ML (FLUP)
}

[Recibido, 16 setembro 2020; aceptado, 2 novembro 2020]

[Araúio, S. (2020). "Este animal aflito": leitura de três últimos homens em tempos apocalípticos pelas mãos de Mary Shelley, Pepetela e Miguel Real. Boletín Galego de Literatura, 57, "Notas", 5-15]

DOI http://dx.doi.org/10.15304/bgl.57.7102

RESUMO Em qualquer contexto literário distópico -obra total ou moldura diegética de uma contra-proposta utópica- a figura do último homem, do indivíduo só, do único sobrevivente, assume-se comummente como o guardião do que foi e toma para si um papel civilizacional. A partir da análise de três romances profundamente distintos -The Last Man, de Mary Shelley (1826), O Quase Fim do Mundo, de Pepetela (2013) e O Último Europeu 2284, de Miguel Real (2015)- foi possível delinear os pontos cardiais destas figuras literárias, mas também filosóficas, e confirmar que a figura querida dos românticos mantém a plasticidade e o potencial sugestivo de antanho.

Palabras Chave Distopia; ficção especulativa; Mary Shelley; Miguel Real; Pepetela.

ABSTRACT In any dystopian literary context - whether a full-fledged dystopian text or as the setting for a utopian counter-proposal -, the last man, the lone individual, the sole survivor is often read as the guardian of that which was and takes on a civilizational role. This analysis of three different novels - Mary Shelley's The Last Man (1826), Pepetela's O Quase Fim do Mundo (2013), and Miguel Real's O Último Europeu 2284 (2015) allowed for the establishing of the key traits shared by these literary and philosophical characters, thus confirming that this figure so well-loved by the Romantics continues to hold considerable plasticity and allusive potential.

KEYWORDS Dystopia; speculative fiction; Mary Shelley; Miguel Real; Pepetela.

Bem sei que non hai nada

Novo en baixo do ceo,

Que antes outros pensaron As cousas que ora eu penso. $E$ bem, ¿para que escribo?

E bem, porque así semos, Relox que repetimos

Eternamente o mesmo.

(Fragmentos de um poema da poetisa galega Rosalía de Castro)

* Verso de António Gedeão. 
Dentro de um contexto literário distópico -quer enquanto obra total, quer enquanto moldura diegética de uma contra-proposta utópica- a figura do último homem, do indivíduo só, do único sobrevivente (dos humanos ou de entre a sua tribo) assume-se comummente como o guardião do que foi e toma para si um papel civilizacional bem longe do conceito nietzschiano homónimo apontado em Assim Falou Zaratustra em contraste com o super-homem. É particularmente no Romantismo oitocentista que encontraremos a figura trabalhada em ficção especulativa (ie textos utópicos e ficção científica), na senda do romance de Jean-Baptiste Cousin de Grainville, Le Dernier Homme (1805), no qual a humanidade perde a capacidade de procriar à exceção de um último casal, decidindo esse último homem, Omegarus, assumir o futuro degenerado da raça humana e assim afastar-se cumprindo o que intui ser o plano de Deus de extinção definitiva. Em 1816 Lord Byron dedica ao tema o poema "Darkness", que será recebido com a atenção crítica que justifica a posterior celeuma com Thomas Campbell, autor de um outro poema, "The Last Man” (1823), que gerará entre os autores a troca de acusações mútuas de plágio. À data do romance de Mary Shelley, 1826, abundam poemas (alguns dos quais anónimos), contos, quadros, óperas e até um poema satírico de Thomas Hood intitulado também "The Last Man" no qual, segundos depois do entusiasmo pelo poder total sobre a Terra que acaba de obter, o homem isolado confronta-se com a incapacidade de ação universal nas mãos de um só.

Momentos de particular produção literária escatológica como o são as transições de século ou as fases de pós-guerra veem uma acumulação deste tipo de personagem a par com os quadros apocalípticos, como apontam diversos estudiosos ${ }^{1}$. Três romances profundamente distintos permitem-nos delinear os pontos cardiais destas figuras literárias, mas também filosóficas, e confirmar que a figura querida dos românticos mantém a plasticidade e o potencial sugestivo de antanho: The Last Man, de Mary Shelley (1826), O Quase Fim do Mundo, de Pepetela (2013) e O Último Europeu 2284, de Miguel Real $(2015)^{2}$.

1 De entre estes, permito-me destacar o volume que Fiona Stafford dedica às primeiras décadas do século XIX, não apenas pela relevância direta para o caso de The Last Man de Mary Shelley mas pela própria interdisciplinaridade cruzada que norteia a análise que faz do fenómeno em The Last of the Race: The Growth of a Myth from Milton to Darwin (Stafford, 1994).

2 Estas obras não são extemporâneas e enquadram-se num momento de transição milenar no qual surge também o romance Oryx and Crake (2003), de Margaret Atwood, o qual é atualmente considerado o mais forte eco desta tradição. 
Em O Quase Fim do Mundo Pepetela arranca o romance com um parágrafo digno do cariz anti-climático do próprio título:

Chamo-me Simba Ukolo, sou africano, e sobrevivi ao fim do mundo. Se o fim do mundo quer dizer o aniquilamento absoluto da humanidade, haverá algum exagero na afirmação, pois escapou alguém, eu, Simba Ukolo, na ocorrência. Isso foi a primeira impressão, sozinho na minha cidade natal. Terrível sensação de solidão e de perda. Mas sobretudo uma tontura de incredulidade. Dava mesmo para acreditar em coisa mais absurda? Viria a descobrir depois, não era de facto o único, havia sobreviventes, embora talvez não fossem todas, as pessoas mais desejáveis com que partilhar os despojos dos biliões de humanos desaparecidos. Foi um quase fim do mundo, esteve mesmo muito perto de o ser em absoluto, o apagamento total da raça humana, percebi mais tarde. (Pepetela, 2014, p. 5)

Assim, pareceria ser em Simba Ukolo que encontraríamos a figura do guardião civilizacional. É ele quem arranca o romance e se depara com a circunstância apocalíptica, é ele quem reúne gradualmente o grupo de sobreviventes que viajará pelo mundo e se constituirá como nova humanidade. No entanto, a narração de $O$ Quase Fim do Mundo não surge envolta num projecto filosófico e Pepetela assegura que o leitor se dará conta disso fazendo a voz narratorial oscilar entre primeira e terceira pessoa e mesmo, por vezes, entregando a narração de primeira pessoa a outros personagens que não o protagonista. Será mais tarde, quando o motivo para a hecatombe mundial estiver prestes a ser deslindado, que conheceremos o personagem que, ele sim, procura resgatar o que havia e o que restou para leitura dos vindouros. Só após cerca de 300 páginas e, já na Europa, Pepetela nos explica de que forma esta mortandade mundial resulta não de uma pandemia, de uma tragédia natural ou de uma guerra. Na realidade, o próprio extermínio é parte necessária do plano tido por utópico por um coletivo no qual se inclui a figura que nos interessará aqui. Os sobreviventes vão recolhendo sinais de tinta que espalham pistas de sítio em sítio dirigindo o caminho dos sobreviventes. Do Vaticano e da Torre Eiffel são conduzidos às portas de Bradenburgo em Berlim. É lá que encontram o dossier de capa azul que "numa escrita nervosa e miúda" (Pepetela, 2013, p. 338) explica os objetivos dos mentores do quase-apocalipse. Uma personagem sem nome apresenta-se como um físico, cidadão dos Estados Unidos e de origem europeia, e declara-se um dos inventores do "Feixe Gama Alfa" que desintegrou grande parte da humanidade. O plano eugénico dos Paladinos da Coroa Sagrada, desenvolvido pelo austríaco Pak-To com vista à "redenção da raça branca, raça tão vilipendiada através do século XX, 
como a culpada de todos os males" (Pepetela, 2013, p. 339), assume um cariz religioso que é explorado ao longo de cerca de oito páginas na então denominada Operação Noé. O físico abraça de tal forma o projeto que violará as regras do mesmo única e exclusivamente para garantir que ele sobreviverá como ideia/ideal a qualquer hipótese de erro. É por isso que viola as regras dos seus chefes, redige o documento e espalha marcas escondidas para permitir aos vindouros recuperar o texto interdito. Sofre com o seu ato de rebeldia mas sente-o como parte do mesmo desígnio utópico, como recurso em caso de insucesso e de os eleitos da gruta/bunker não sobreviverem:

Considero criminoso duvidar da mais ínfima parte dos ensinamentos de PakTo, mas é muito perturbadora a ideia que possamos estar errados e afinal, a gruta não oferecer tal protecção à vida que está a albergar. Escondi a dúvida e a minha angústia, pois não podia revelar tão pecaminoso cepticismo.

Amanhã é o dia último desta era vergonhosa de crime e vício, pois as armas serão accionadas. Mas eu tenho esta dúvida que não posso revelar a ninguém, por ser fatalmente considerada uma magna traição e uma blasfémia inconcebível. Por isso resolvi deixar uma pista. Se por acaso estivermos errados e não sobrevivermos, talvez outros sobreviventes queiram saber o que aconteceu, mesmo que seja só daqui a dez mil anos. Se estivermos mesmo certos, apagarei a dúvida e qualquer vestígio que tenha deixado, como este documento secreto. (Pepetela, 2013, p. 343)

Conhecido o plano de genocídio universal, o narrador assume a $3^{\text {a }}$ pessoa para uma reflexão filosófica final, plena de questionamentos abertos que o - e nos - deixam entre a resignação depressiva que explana e a esperança com que termina:

Ao fim de algumas gerações os sobreviventes dos cataclismos vão perdendo conhecimentos, substituem-nos por fantasias, gerações seguintes adulteram ainda mais, e tudo acaba por ficar amalgamado numa religião qualquer. Mas o verdadeiro conhecimento científico, a explicação coerente do porquê de fazer determinado gesto ou utilizar uma certa técnica, esse conhecimento perdeu-se para sempre. Para sempre? Ao fim de milhares ou centenas de milhares de anos, acabam por descobrir o que já se/ sabia há muito, a civilização volta a instalarse, não igual à que ora antes, mas com alguns princípios básicos comuns. A teoria do eterno retorno? Pode ser. Uma civilização desenvolve-se até poder fabricar as armas capazes de a destruir, tal é o seu destino. E acaba por deixar poucos vestígios, ou então são vestígios incompreensíveis para as gerações seguintes. E o destino do homem é destruir-se, para recomeçar tudo de novo? (Pepetela, 2014, pp. 356-357) 
Paradoxalmente, este físico e o seu intuito de comunicar com os vindouros e de preservar a experiência existencial de uma civilização perdida correspondem às figuras dos romances de Mary Shelley e Miguel Real, sendo que essas últimas são vítimas e não autores da devastação à qual, ao contrário do físico de Pepetela, sobrevivem.

No caso de Miguel Real, o seu O Último Europeu 2284 narra a destruição de uma civilização e não da humanidade, mas assume de forma explícita que nessa civilização residia o pináculo da Humanidade como um todo, pelo que preservá-la assume uma importância existencial universal. O seu protagonista é o último europeu que deixa um manuscrito entregue aos sobreviventes utopicamente isolados nos Açores para que os méritos da civilização europeia sejam recuperáveis depois da mortandade infligida pelos invasores asiáticos. O texto incorre de forma consciente e por vezes irónica na utilização de uma série de estereótipos para a caracterização do Outro exterior à Europa, e certamente exterior à Nova e Novíssima Europas. O politicamente incorreto perpassa o texto, mas é inegável que há momentos em que, a traço grosso, Miguel Real denota um conhecimento profundo da história cultural das várias civilizações. O futuro imaginado tem raízes no passado histórico, como quando refere o isolacionismo norte-americano do séc. 23 como um regresso à doutrina Monroe do século XIX (cf. Real, 2015, p. 212). Que pareça antecipar a campanha de Trump um ano depois da escrita do romance acresce ao matiz irónico, mas certeiro, de muitas das análises, assumidamente redutoras mas cardinais, de Miguel Real. É assim quando fala do conservadorismo e da religiosidade dos americanos (cf. Real, 2015, pp. 144, 227) e da sua "permanente curiosidade infantil" (Real, 2015, p. 211), do "sentimento de ausência de piedade que sempre caracterizou os impérios orientais" (Real, 2015, p. 113) ou do atraso e "irracionalismo religioso" do império russo (Real, 2015, p. 199). Ora, o excepcionalismo europeu que os personagens abraçam -"Somos felizes porque nos separámos da restante humanidade" (Real, 2015, p. 111) - não impede, para lá de todos os abundantes encómios, ocasionais críticas, como, por exemplo, quando se refere aos abusos ambientais dos europeus (Real, 2015, p. 81). Algumas delas, contudo, serão mais sarcásticas, como quando elogia a superioridade das universidades do Império Americano em relação às da Nova Europa:

$\mathrm{E}$ a verdade deve ser dita, as universidades do Império americano são superiores às da Nova Europa [...]. De facto, as suas universidades constituem autênticas concentrações de debate e de investigação que aproximaram, em muito, os seus resultados científicos e tecnológicos dos da Nova Europa. 
Em nome da humanidade do homem, como alegam, recusaram a aplicação do hipercórtex ao cidadão, mas desenvolveram em grau extremo a robótica, hoje denominada Biótica, criando androides auxiliares para todas as actividades, bem como uma exploração intensiva de massas de escravos, comprados em quantidades astronómicas aos Coronéis da América Latina e aos Mandarins da Grande Ásia que governam a África. (Real, 2015, pp. 223-224)

Neste referido hipercórtex de criação biológica reside a substância da supremacia da civilização neo-europeia imaginada por Miguel Real. Assim, e sem contrariar a tendência coeva para falarmos em pós-humano, mas afirmando encontrar nesse um humano mais humano, Real falará de um bomo bumanus, possuidor de mais 500 centímetros cúbicos de caixa craniana, e por isso mais livre daquilo que nele encontra de vil -da "carga animal", do "determinismo do corpo", "da sua animalidade, da recordação do cheiro e do sabor do sangue, do gosto da carne, crua ou cozinhada" (Real, 2015, pp. 54, 54, 55). Com esta mudança, vem também a extinção de qualquer raciocínio tido por ilógico:

Para nós, de facto, a História começou em 2184, quando a humanidade se libertou definitivamente do determinismo do corpo e o Homem se tornou um puro cérebro racional, um puro ser pensante, sem crenças metafísicas, religiosas ou científicas, substituídas pela certeza de que um problema complexo se divide em elementos simples, os quais (ou a maior parte dos quais), se solucionados, solucionam o problema. (Real, 2015, p. 54)

É, portanto, uma conquista europeia mas de superior interesse para toda a Humanidade o que o Reitor tenta preservar depois de escolhido para o efeito pelo Conselho dos Pantocratas, para que vindouros europeus humanistas possam saber que

existiu uma Europa Humanista, racional, bela, justa, próspera, abastada, igualitária, comunitária, onde todos os cidadãos eram felizes e a liberdade absoluta, já que, mesmo quando os conselhos do Grande Cérebro Electrónico desaprovavam uma acção individual, nunca a proibiam e encontravam sempre meios e instrumentos de os requerentes viverem mental e intensamente os seus desejos, como se em concreto os tivessem vivido, assim registando na memória a sua aparente experiência existencial. (Real, 2015, p. 18)

Residirá, assim, na Crónica da Criação e Extinção da Nova Europa (Real, 2015, p. $37^{3}$ ), o "anúncio da existência da mais perfeita civilização criada pela

3 Numa fase posterior, o Reitor decide renomear o manuscrito: "Finalmente, decidi-me pelo título definitivo do livro: Crónica da Nova Europa, anulando 'Criação' e 'Extinção'" (Real, 2015, p. 196). 
humanidade" (Real, 2015, p. 29). Ainda assim, reconhecerá mais tarde que reside também no manuscrito a sua tentativa de conferir sentido à sua própria existência individual (Real, 2015, p. 184). Este Reitor, afinal, é quem nos conta a forma como falava às crianças do Colégio nos Açores "no prazer como motor ético de vida e na utilidade como critério social" (Real, 2015, p. 190) e assim procura fundir, através da redação do manuscrito, o compromisso coletivo e civilizacional (quase utópico) com o alívio de um sofrimento existencial. Parece, assim, corresponder à figura que anos antes, em Introdução à Cultura Portuguesa, Miguel Real tinha delineado para descrever o intelectual português:

Cumprindo a sua função, o intelectual, de actividade social marcante na história de Portugal, não tem sido o erudito, o estudioso, o académico, o especulativo, ao modo de Descartes, Kant, Hegel ou Freud, construtores de novos sistemas teóricos, que posteriormente influenciam todas as esferas da actividade humana, revolucionando a sociedade, mas aquele que no seu destino individual, no seu sofrimento existencial e na sua obra, habitualmente criada em condições pungentes ou dramáticas, se oferece como sentido de uma alternativa pátria, exprimindo uma visão social e cultural que, pragmática ou utópica, não é considerada (até recentemente) como legitimamente válida pelas instituições vigentes (o Estado, a Universidade e a Igreja). (Real, 2011, p. 31)

Este homem sente-se sempre como um agente de um esforço coletivo, mas vai assumindo a sua solidão enquanto líder que resta à comunidade dos viajantes que se refugiam na ilha do Pico. Essa consciência é fulcral desde a viagem, durante a qual faz um discurso que equaciona vir a ser histórico caso sobrevivam e fundem de facto uma nova civilização (Real, 2015, p. 133). No entanto, este personagem ao leme de um novo Império tem muito pouco da ilusão adolescente de um D. Sebastião (Real, 1998, p. 56) e muito mais de uma consciência quase sartriana de responsabilidade universal colocada aqui em situação limite: "Éramos provavelmente os últimos, os últimos dos últimos, os derradeiros. O que significava que também éramos os primeiros - os primeiros dos primeiros - de um futuro por construir. Não havia maior responsabilidade" (Real, 2015, p. 133). À medida que a experiência utópica avança, o Reitor agarra-se cada vez mais à noção de que se trata de um esforço coletivo, uma missão partilhada que se sobrepõe a ele próprio (cf. Real, 2015).

O desejo de preservar a matriz europeia é de urgência absoluta, à medida que o tempo os afasta da excelência que outrora tinham atingido e traz o 
pavor da decadência: "Não éramos já animais, mas tínhamos deixado de ser totalmente racionais. Em pouco menos de um mês regredíramos, tínhamo-nos tornado apenas humanos.” (Real, 2015, p. 139). Há um culto do Europeu que é quase simbólico, como quando se alumia com ânforas de azeite romanas para escrever à noite (Real, 2015, p. 30) ou quando usa o lastro da cultura europeia para, através de Homero, Hesíodo, Vergílio, Plauto, Esopo, lendas medievais germânicas e aventuras ultramarinas ibéricas, levar a cabo a educação cívica dos seus pupilos no Pico:

Extraía sempre a mesma conclusão, as forças bestíferas que tinham levado à explosão da violência e da posse no passado tinham sido as mesmas que actualmente tinham tentado promover a extinção da Nova Europa. (Real, 2015, p. 188)

A história e a História são cruzadas ao longo do romance e usadas para refletir a essência do Humano. Por vezes, Miguel Real obriga-nos a confrontar a perigosidade da História ao intersectar momentos passados com comportamentos futuros, como quando coloca os Mandarins a oferecerem a hipótese de uma transferência dos dominados em lugar da extinção que é, afinal, a solução que desejam (Real, 2015, p. 109) -ser conduzido à memória da 12 hipótese nazi de um Madagáscar para judeus é um processo pretendido e trabalhado pelo escritor. A urgência é conferida pelo confronto com a "agonia da Nova Europa” (Real, 2015, p. 146) e com o horror eugenista e totalitário desenvolvido pelos Mandarins para os reféns europeus e do resto do mundo (por exemplo, para África decretaram limite de vida aos 80 anos, assassinando os africanos quando chegam a essa idade [Real, 2015, p. 147]). É o confronto com todo o detalhe aterrador do domínio asiático, culminado na certeza do assassinato dos elementos do Conselho dos Pantocratas, que impulsiona o Reitor e os sobreviventes isolados a uma conclusão responsabilizante: "Verdadeiramente, agora somos mesmo os últimos europeus, os últimos dos genuínos neo-europeus". A repetição lexical e a cadência da redundância semântica denunciam o peso intelectual e emocional deste momento da vida do Reitor. Algumas páginas mais tarde, a distopia final que exigia a memória escrita como única esperança é contrariada pela tentativa de reconstrução de modelo civilizacional através do isolamento. O primeiro nascimento naquela comunidade da ilha do Pico marca o renascimento da crença na sobrevivência cultural, para lá de animal:

Como condutor da comunidade, foi-me dado o privilégio - o que digo?, a superbíssima honra - de ser o primeiro homem a pegar, a acarinhar e a balouçar 
o bebé [...] deram comigo a amparar entre os braços aquele pequenino ser que para todos nós representava os dois símbolos máximos da humanidade - a renovação da vida natural e o preenchimento voluntário do tempo futuro pela humanidade. (Real, 2015, p. 174)

O fracasso do projeto dar-se-á a par com a morte do Reitor, reforçando o valor do manuscrito que permitirá a outros tentar de novo. No entanto, é já sem ânsia e nem sequer crença que o protagonista protege o manuscrito para lá de si próprio:

A convivência com a natureza simplificou-me o espírito, desinquietou-me, tornei-me mais sereno, resignado a aceitar a inevitabilidade do fim [...]. A nova Europa morreria, mas renasceria um dia, porventura não tão perfeita. Decidi não ordenar que o livro fosse destruído após a minha morte, já que, enternecido pela letra da menina e pela leitura que outras crianças faziam, sentia um despudorado orgulho quando the chamavam 'o nosso livro'. Não tinha o direito de o fazer desaparecer [...]. [S]erá [a menina] a guardiã da história da Nova Europa. (Real, 2015, pp. 255, 274)

É também através de um manuscrito que Mary Shelley retrata em 1826 a total extinção da Humanidade excepto um último homem, como resultado de uma peste num mundo interconectado. Curiosamente, o momento diegético da descoberta do que aconteceu é colocado no tempo histórico da vida da autora, mas a história preservada nos fragmentos encontrados nos subterrâneos da Sibila de Cumas teria tido lugar em 2093, momento em que os autores do escrito têm apenas uma vaga esperança de futuro:

And who will read them? Beware, tender offspring of the reborn world beware, fair being, with human heart, yet untamed by care, and human brow, yet unploughed by time - beware, lest the cheerful current of thy blood be checked, thy golden locks turn grey, thy sweet dimpling smiles be changed to fixed, harsh wrinkles! (Shelley, 2004, p. 348)

A estratégia narrativa e o protocolo de leitura estabelecidos por Mary Shelley obrigam-nos a ficar na dúvida de Lionel Verney, uma vez que acedemos ao futuro a partir do passado. A história narrada nos fragmentos parte do percurso convencional da história de famílias e nações que nos apresenta ao narrador-protagonista Lionel Verney e à república inglesa e avança para os efeitos da mortandade num planeta tomado pela peste e para a profunda solidão de um único sobrevivente, isolado e saudável. A dimensão existencialista é profundamente vincada. Ao contrário dos protagonistas de Pepetela e 
Miguel Real -eles também isolados na sua missão ou, pelo menos, na perceção que têm dela- Lionel Verney está a partir de certo momento completamente só e confrontado com o sem-sentido da existência humana. A Natureza é inimigo do Humano, personifica a peste (Fisch, 1993, p. 267) e portanto a Arte é buscada uma e outra vez como refúgio pelos sobreviventes. No entanto, são constantemente confrontados com a indiferença da Arte e da História e com o silêncio dos homens e mulheres do passado que deixam de ser agentes e intérpretes da vida humana. Ainda assim, Lionel Verney continua a procurar sentido, rejeitando a natureza em prol da obra humana

No, no, I will not live among the wild scenes of nature, the enemy of all that lives. I will seek the towns - Rome, the capital of the world, the crown of man's achievements. Among its storied streets, hallowed ruins, and stupendous remains of human exertion, I shall not, as here, find everything forgetful of man; trampling on his memory, defacing his works, proclaiming from hill to hill, and vale to vale - by the torrents freed from the boundaries which he imposed - by the vegetation liberated from the laws which he enforced - by his habitation abandoned to mildew and weeds, that his power is lost, his race annihilated for ever. (Shelley, 2004, pp. 366-367)

I4 É apostando na existência de qualquer tipo de leitura futura para o manuscrito que Verney o deixa num monumento -manuscrito que virá a ser lido 200 anos antes. Escolhe Roma, como gesto de resgate do humanismo que pretende testemunhar e preservar. Citando Barbara Johnson, "[i]n going to seek other survivors in Rome, birthplace of bomo bumanus, Mary Shelley's last man performs the humanist gesture par excellence: he seeks to live the death of all of humanity" (Johnson, 1993, p. 263).

Utópicos humanistas ou etnocêntricos, de África para Bradenburgo, em Roma ou na ilha do Pico, estes homens funcionam como uma espécie de 'L'uomo vitruviano' ao retratar as várias dimensões e perspetivas da existência temporal e espacial do humano, com um desejo constante, aparentemente inerente ao ser humano: ser testemunha do vivido, condensando, assim, em si os frutos e as sementes de séculos ou milénios de civilização.

\section{Bibliografia}

Fisch, A. A. (1993). Plaguing Politics: AIDS, Deconstruction, and The Last Man. En A. A. Fisch, A. K. Mellor e E. H. Schor (Eds.). The Other Mary Shelley: Beyond Frankenstein (pp. 267-286). Oxford University Press. 
Johnson, B. (1883). The Last Man. En A. A. Fisch, A. K. Mellor e E. H. Schor (Eds.). The Other Mary Shelley: Beyond Frankenstein (pp. 258-266). Oxford University Press.

Pepetela (2013). O Quase Fim do Mundo. Leya

Real, M. (1998). Portugal Ser e Representação. Difel

Real, M. (2011). Introdução à Cultura Portuguesa. Planeta Manuscrito

Real, M. (2015). O Último Europeu 2284. Publicações Dom Quixote

Shelley, M. (2004). The Last Man. Wordsworth Classics

Stafford, F. J. (1994). The Last of the Race: The Growth of a Myth from Milton to Darwin. Clarendon Press. 